\title{
Expertise, argumentation, and the end of inquiry
}

\author{
Axel Gelfert \\ Department of Philosophy \\ National University of Singapore \\ 3 Arts Link \\ 117570 Singapore \\ email: axel@gelfert.net
}

\begin{abstract}
This paper argues that the problem of expertise calls for a rapprochement between social epistemology and argumentation theory. Social epistemology has tended to emphasise the role of expert testimony, neglecting the argumentative function of appeals to expert opinion by non-experts. The first half of the paper discusses parallels and contrasts between the two cases of direct expert testimony and appeals to expert opinion by our epistemic peers, respectively. Importantly, appeals to expert opinion need to be advertised as such, if they are to sway an epistemic peer. The second half of the paper sketches a theoretical framework for thinking about assessments of expertise in a unified way, via a 'default and challenge' model that emphasises the need for a version of conversational scorekeeping. It is through such scorekeeping that interlocutors can track and coordinate their differences in epistemic outlook. The paper concludes with a genealogical perspective on the function of (attributions of) expertise: acceptance of another's appeal to expert opinion may be construed as tacit agreement that inquiry, for now, has been taken far enough.
\end{abstract}

Keywords: expertise, testimony, expert opinion, social epistemology, default-and-challenge model

\section{Introduction}

The present paper is based on the idea that the problem of expertise provides an occasion for a rapprochement between social epistemology - conceived of as the subdiscipline of contemporary analytic philosophy that deals with the social dimensions of the concept of knowledge - and the more 'hands-on' approaches favoured by argumentation theory and science studies. The concept of expertise lends itself to such an interdisciplinary agenda since it has been discussed, in different 
guises and at different levels of resolution, by contributors from all the relevant disciplines. While this is not the place for surveying the disciplinary landscape with an eye towards identifying areas of overlap between the different discourses, it is nonetheless instructive to first approach the question of expertise from within one discipline (here: social epistemology), before investigating how the results of such an analysis can be extended to, or contrasted with, the questions that dominate discussions of the concept of expertise in neighbouring disciplines.

The rest of this paper is organised into five sections. In the next section (Section 2), I shall discuss what I call 'the received view' of expertise in social epistemology. According to this view, the problem of expertise reduces to the problem of deciding when to accept expert testimony. However, as I argue in Section 3 , such an undue emphasis on testimony as the means of transmission of expert opinion obscures the deeper question of what grounds expert authority, and how one should weigh claims to expertise against first-hand evidence. Furthermore, as discussed in Section 4, many expert opinions are not communicated to us by putative experts themselves; rather, we encounter them in the form of appeals to expert opinion by our peers who, for all we know, are non-experts themselves. Section 5, drawing on recent work by Alvin Goldman and Douglas Walton, contrasts both scenarios - direct expert testimony, and appeals to expert opinion by our epistemic peers - before sketching a theoretical framework for thinking about assessments of expertise in a unified way, via a model of 'conversational scorekeeping' inspired by Robert Brandom's terminology of deontic statuses and attitudes. In the final section (Section 6), I suggest that the envisaged rapprochement between social epistemology and argumentation theory gains some support from a recent strand of epistemology that aims to shed light on the concept of knowledge by investigating its function rather than its conceptual ingredients.

\section{The expert as witness: the received view}

On the standard view in contemporary social epistemology, the concept of expertise derives its epistemological significance from the fact that, in our capacity as members of highly differentiated, technological societies and citizens of liberal-democratic states, we constantly need to rely on expert testimony, both for the purpose of collective decision-making and in the choices we make as individuals. From this perspective, the epistemic problem of expertise thus reduces to the question of when to accept expert testimony. Nothing reflects this identification of the issue of expertise with the phenomenon of reliance on expert testimony better than the title of an influential paper by social epistemologist Alvin Goldman: 'Experts: Which Ones Should You Trust?' (Goldman 2001)

In contemporary analytic philosophy, the rise of interest in socialepistemological issues is inextricably linked to the epistemology of testimony, which, 
after what is often - historically inaccurately - portrayed as a period of neglect, was 'put on the philosophical map' again by the publication of C.A.J. Coady's Testimony: A Philosophical Study (1992). As Coady sees it, the philosophical debate about testimony centres primarily on a wholesale justification of testimony as a source of knowledge. In virtue of what are our testimony-based beliefs epistemically justified? Reductionists insist that whatever epistemic justification testimony-based beliefs enjoy must ultimately be reducible to more basic sources of justification, viz. perception, memory, and inference. Anti-reductionists, by contrast, are guided by the idea that testimony is a sui generis source of epistemic warrant. Much of recent epistemology of testimony, and indeed of social epistemology more generally, remains indebted to this clash of intuitions regarding the justificatory basis of testimonial beliefs. It is not without irony that Coady's emphasis on the applications of testimony - around a quarter of his book is devoted to to the role of testimony in historiography, psychology, and the law - had an almost negligible effect on the early debate in contemporary epistemology of testimony. Coady makes a helpful distinction between 'formal testimony' (the evidence given by persons in a legal or 'quasi-legal' context) and a wider notion of 'natural testimony' (Coady 1992: 26), where the latter is understood as an umbrella term for any knowledge gained on the basis of the say-so of others. On the face of it, expert testimony will typically - though not necessarily be located towards the 'formal' end of the spectrum of testimonial interactions.

The emphasis, in contemporary social epistemology, on testimony as the most obviously 'social' among our sources of knowledge is at least partially motivated by a desire to preserve as much of traditional epistemology as possible. If the concept of testimony 'takes care of' the social dimension of knowing, other parts of our epistemological framework remain untouched, or so the implicit reasoning seems to go. A number of epistemologists (e.g., Kitcher 1994, Goldberg 2010) have embraced the label of 'minimal social epistemology', according to which the social world intrudes on epistemology because it affords new social routes to knowledge and belief, the reliability of which stands in need of assessment. Philip Kitcher sums up the fundamental tenets of 'minimal social epistemology' as follows:

(1) Individuals are the primary subjects of knowledge. To ascribe knowledge to a community is to make an assertion about the epistemic states of members of the community.

(2) $X$ knows that $p$ if and only if (a) $X$ believes that $p$ and (b) $p$ and (c) $X$ 's belief that $p$ was formed by a reliable process.

(3) The reliability of the process that produces $X$ 's belief that $p$ depends on the properties and actions of agents other than $X$. (Kitcher 1994: 113)

Minimal social epistemology thus explicitly rejects the need for a 'communitarian epistemology' (Kusch 2002) that conceives of knowledge as a social status. However, as John Hardwig points out in his analysis of the role of trust in knowledge, an excessively individualist conception of knowledge and evidence is itself problematic, since it would seem 'that there can no longer be knowledge in many scientific 
disciplines because there is now too much available evidence' for any one individual to assess all on her own (Hardwig 1991: 699). Science, thus, appears in danger of becoming a victim of its own success, its wealth of evidence and data undermining the very knowledge it claims to provide us with.

Hardwig argues for a revision of our philosophical understanding of knowledge, lest we fall prey to this twisted form of scepticism. But even granting the coherence of our philosophical concept of knowledge, whether suitably revised or not, there remains an asymmetry between those who can legitimately claim to have expert scientific knowledge and those who need to rely on the former's testimony. Goldman distinguishes between three scenarios: First, the 'novice/expert problem', viz. the paradigmatic case of a layperson being confronted with a given expert opinion, the truth or falsity of which she lacks the expertise to assess directly; second, the 'novice/2-expert problem', in which the novice must adjudicate between two conflicting expert opinions; and finally, the 'expert-expert' problem, 'in which experts seek to appraise the authority or credibility of other experts' (Goldman 2001: 90). While Goldman focuses on the case of competing testimony from two rival experts (i.e., the 'novice/2-expert problem'), his recommendations for how to assess the reliability of said experts also extend to the single-expert case. Specifically, Goldman identifies 'five possible sources of evidence that a novice might have' (Goldman 2001: 93) for trusting, or withholding trust from, a putative expert: 1.) arguments supporting the expert's views, or rebutting rival opinions; 2.) agreement from other putative experts; 3.) 'appraisals by "meta-experts"; 4.) evidence of relevant interests and biases on the part of the expert; and 5.) evidence of the expert's past track record. Several of these criteria will be revisited in later sections, and their heuristic value discussed; first, however, I wish to prise apart questions of (expert) testimony from expertise more broadly construed.

\section{Expertise, testimony, and authority}

In recent years, a certain dissatisfaction has set in with respect to the traditional conceptions of testimonial interaction that dominate the epistemological literature. In what Jonathan Adlers refers to as the 'null setting', the recipient of a piece of testimony lacks detailed background knowledge of the speaker (though she may have access to purely circumstantial evidence, such as the speaker's demeanor or his looking like a policeman) and makes no 'attribution of expertise to a speaker on certain topics'. She does not engage the speaker in extended conversation or argument; testimonial interactions are brief, one-off affairs that produce and sustain a particular belief that, if successful, is passed on from the speaker to the hearer. (Adler 2010) Critics of this way of describing what happens when one person trusts another for knowledge have pointed out that, by decontextualising the setting in which testimonial exchange takes place, 
we [lose] much much of the intutitive 'grounds' we normally assume as the everyday explanation of our trust - information about the speaker or the speaker's type and/or characteristics of the specific practice of testimony in which we are involved, with its own, more or less institutionalized, model of authority, etc. (Olmos 2008: 58)

Indeed, it should be obvious that an account of testimony that is stripped of all empirical constraints does not lend itself to making sense of specific practices of testimony - least of all in the case of expert testimony, which is explicitly excluded from the 'null setting', due to the prohibition on attributions of expertise by the recipient of testimony.

In the previous section, I voiced scepticism about the usefulness of assimilating issues of expertise, broadly construed, to the question of when it is rational to accept expert testimony. We are now in a position to see why focussing on expert testimony is insufficient to elucidate the nature of expertise. For one, as just mentioned, the standard model of the 'null setting' in analytic epistemology of testimony does not easily lend itself to homing in on the right reference class of cases of expert testimony. Furthermore, even if one could independently identify relevant cases of expert testimony, attempting to understand expertise qua expert testimony would misrepresent the characteristic kind of epistemic dependence that is involved in relying on another's expertise. In cases of direct empirical testimony among equals, what grounds the (successful) reliance of the hearer on the speaker is the 'purely positional advantage' (Williams 2002: 42) that allowed the speaker to acquire the requisite knowledge in the first place: The speaker was simply in the right place at the right time, whereas the hearer was not. If the recipient of the testimony could travel back in time and switch places with the testifier, she could have acquired the original knowledge just as directly as the latter. In the case of reliance on another's expertise, the epistemic asymmetry runs deeper than mere difference in spatio-temporal location. ${ }^{1}$

One way of bringing out what is at stake in the difference between the two kinds of epistemic dependence, is via the twin notions of authority and evidence. One frequent recommendation in connection with testimony is the demand to weigh any testimonial claim against the empirical evidence. As David Hume succinctly put it, 'a wise man [...] proportions his belief to the evidence' (1748: EHU 10.7) - where such evidence need not be confined to beliefs or facts that speak directly to the truth or falsity of the claim in question, but may also include background beliefs or considerations of plausibility. However, in the paradigmatic instances of reliance on another's expertise - for example in scientific or medical contexts - it is often far from clear what should count as evidence in the first place. What is evidence need not be self-evident to, say, the patient, who may after all have consulted his family doctor's expertise precisely in the hope of gaining greater clarity as to whether certain

\footnotetext{
${ }^{1}$ While spatio-temporal location is of paramount importance in eyewitness testimony, for second-hand report or hearsay, what matters may be the recipient's location in the social network across which a report is spreading.
} 
empirical findings, e.g. some minor ailments, are indeed evidence of an underlying disease. Similarly, disagreements between experts (e.g., about the health risk of living near a mobile phone tower) often take the form of disagreements about which empirical findings (e.g., geographical clusters of cancer cases) should be accorded the status of evidence - as opposed to, say, statistical background noise. The notion of expertise is thus intimately related to that of authority - not simply the procedural authority to decide which considerations or empirical findings ought to be considered relevant to decision-making, but also the epistemic authority that derives from a wide range of experience and a track record of well-honed judgment, both of which may or may not be accessible to a layperson (let alone assessable by her). As Michael Strevens puts it with respect to appeals to scientific authority, '[n]o one normally doubts that the needle pointed where it was said to point, or that the rat went where it was said to go, or that the survey data came out in just the way reported in the journals'. Yet, as a matter of fact, '[s]ome scientists have better reputations for producing reliable, artifact-free experimental data than others', and ' $[\mathrm{t}]$ heir results, as a consequence, have greater authority'. It is for this reason, Strevens argues - rightly, in my view - that 'authority seems a better rubric for the discussion [of scientific expertise] than testimony' (Strevens 2010: 295).

\section{Expert testimony vs. appeals to expert opinion}

Shifting the focus away from expert testimony qua testimony towards the more general question of how expertise confers epistemic authority is advisable for two, related reasons. First, in overt cases of reliance on another's expertise - as, for example, in the case of the patient seeking medical advice or of the government commissioning a study of the environmental effects of a certain piece of legislation not only is the requisite testimony typically solicited rather than volunteered, but the pool of potential testifiers is actively restricted to include only a specific group of people. Unlike in the standard case of testimony discussed in the epistemological literature, we do not typically - at least not in the paradigmatic cases that demarcate reliance on experts as a distinct class of epistemic dependence - come across a piece of testimony and then ask ourselves whether the testifier is an expert or not. Rather, we first identify putative experts and then solicit their testimony. (We may, of course, subsequently come to question their standing as experts, but we typically require special reasons for doing so.) Much effort, both implicit and explicit, goes into the selection of experts, in terms of background assumptions as well as institutional organisation. Yet it is precisely this richness of context that renders expert testimony an interesting contrast to the underdescribed - yet, as Olmos puts it, 'allegedly basic' (Olmos 2008: 59) - case of natural testimony as mere one-off interaction with an epistemic equal. Thus, Kauffeld and Fields (2003) argue that formal testimony, 
as a form of testimony [...] that makes explicit much that is assumed or goes unremarked upon in ordinary conversational settings, [...] can give us guidance as to where we should be looking in these less formal contexts to find the element that we need. (Kauffeld and Fields 2003: 3)

Formal testimony is understood by Kauffeld and Fields as 'that which is delivered before courts of law and commissions of inquiry' (ibid.), yet it is easy to see how the same considerations extend to other, equally highly regulated and institutionally entrenched forms of consulting experts, e.g. in the medical profession.

Second, we often encounter expert claims not in the form of direct testimony by the putative experts themselves, but via appeals to expert opinion by non-experts. Assuming, for the sake of simplicity, that we are dealing with the familiar two-person set-up, one of the conversational partners ('the speaker') might, in the course of a conversation or argument, appeal to an expert opinion in an effort to sway his interlocutor (the 'hearer' or 'respondent'). In order for this appeal to be successful, in the sense of lending the speaker's argument additional weight in the eyes of the hearer, it is important that it be advertised as such. To be sure, the speaker might try to pass himself off as an expert, and might just get away with it, but if the interaction between the two partners is sustained over time, the risk of being found out is high (and the corresponding social sanctions might be severe), especially in cases where the speaker cannot be certain that his interlocutor is less well-informed than he is. A less risky strategy - and indeed the only one that has any chance of boosting the hearer's confidence in a claim beyond the initial credibility it would have, were it presented as the speaker's own opinion - is for the speaker to advertise the fact that he is himself relying on an expert's epistemic authority. Rather than pretend to be an expert himself, the speaker thus adopts the role of a 'conduit' for an expert's authoritative claims. From the perspective of the hearer, this lowers the bar for warranted trust in the claim in question, since it is no longer the expertise of the speaker that is at issue, but his ability to identify relevant expert opinions and his willingness, on this occasion, to report them correctly. The latter may still be uncertain, or even controversial: Is the cited expert indeed a relevant authority? Does the speaker report her views accurately? It is for this reason that, as Douglas Walton puts it, 'it is proper for the respondent to ask critical questions concerning the documentation of the appeal to authority' (Walton 1997: 226).

While much of the subsequent discussion will refer back to the interaction between expert and layperson, it is important to reiterate the point that expert testimony is but one facet of how expertise manifests itself in argumentation. Of equal importance are appeals to expert opinion in everyday dialogue between two arguers of similar epistemic standing. Whereas the expert-layperson transaction is best understood as a 'knowledge elicitation (or information-seeking) dialogue', through which expert opinions are extracted, the interaction between arguer and arguer involves 'the deployment of the extracted opinion by a proponent in a critical discussion, in order to support his side of an argument against a respondent' (Walton 
1997: 226). The latter requires - in broadly Gricean fashion - a recognition, on the part of the respondent, of the speaker's intention to be perceived as making an appeal to an external authority; in other words, a speaker's appeal to expert opinion depends for its success on the willingness on the part of the respondent to accept the speaker's role as a 'conduit', through which she can vicariously tap into the cited expert's knowledge.

\section{Argumentation and scorekeeping}

The recipient of expert testimony and the participant in a dialogue who is confronted with an appeal to expert opinion both share the same predicament: they need to ascertain whether the epistemic authority they are asked to submit to is genuine. Does the putative expert indeed have the relevant expertise and, in the case of an appeal to expert opinion (e.g., in a persuasion dialogue among epistemic equals), are the expert's views adequately reported and deployed in a coherent and consistent way? In the present section, drawing on work by Alvin Goldman $(1999,2001)$ and Douglas Walton (1997, 2008), I shall discuss the role of argumentation in each of the two scenarios, before sketching a theoretical framework for thinking about assessment of expertise in a unified way, viz. in terms of a practice of (a version of) conversational scorekeeping.'

At the end of Section 2, I listed Goldman's five sources of prima facie evidence 'for trusting one putative expert more than another' (Goldman 2001: 93). The first of these will be my main concern, at least as far as pertains to direct expert testimony. In Goldman's words, this source consists in '[a]rguments presented by the contending experts to support their own views and critique their rivals' views' (Goldman 2001: 93). A range of scenarios are conceivable, depending on how the layperson encounters the experts' arguments and their opponent's rebuttals. If, for example, the layperson consults published expert opinions on a topic of known controversy (say, the economic cost of global warming), she might look for argumentative strategies of rebutting opposing views in the documents she consults. Do rebuttals rely on the same evidence as the positive thesis defended by the respective authors? Is the factual characterisation of the opposing view charitable in that defenders of that view could accept it? Not all experts will be equally forthcoming with arguments and information. ${ }^{2}$ Not least in the case of scientific controversies, arguments directed at other experts may not be accessible to the layperson, either because she lacks familiarity with (or access to) the relevant sources (e.g., academic journals), or because understanding the arguments would itself require a degree of expertise that the layperson cannot hope to acquire.

\footnotetext{
${ }^{2}$ Matheson (2005: 152) suggests that interpretative charity, while also making a contribution to a speaker's 'dialectical performance', should be considered an indicator of 'moral superiority', not (mere) 'rhetorical superiority'.
} 
It is helpful, in this context, to distinguish within the experts' discourse between esoteric and exoteric claims (Goldman 2001: 94). Esoteric statements are those that 'belong to the relevant sphere of expertise' and as such are inaccessible either epistemically or semantically - to the layperson $N$. Exoteric statements, by contrast, lie outside the sphere of expertise; their truth-value, Goldman argues, may be accessible to $N$, 'either at the time of their assertion or later' (ibid.). The challenge for the lay recipient of expert testimony lies in moving from the exoteric part of the experts' discourse to acceptance (or rejection) of the esoteric claims in question. As Oliver Scholz (2009) points out, the divide between the exoteric and esoteric parts of expert discourse is sometimes exaggerated and its unbridgeability often merely alleged. Thus, Hardwig writes, with respect to both 'an expert's good reasons for believing that $p$ ' and an objective (God's-eye?) justification of 'why these are good reasons': 'If I do not know these things, I am in no position to determine whether the person really is an expert.' (Hardwig 1985: 340) This, however, is certainly too pessimistic, for it overlooks that the line between (epistemically) esoteric statements and their exoteric counterparts is not as strict as it may seem. Instead, as Scholz puts it, 'the epistemic status of a given statement may change from one time to another since the epistemic standpoint can change from one time to another' (Scholz 2009: 201 ) - hence the value and significance of expert predictions: Whether or not there is going to be a lunar eclipse a year from today is at present an epistemically esoteric statement for those of us who are no astronomers, yet when the time comes, the claim can be verified through simple visual inspection (assuming a clear night).

Experts, of course, are often - especially in the context of legal proceedings or public hearings - asked to translate their opinions and findings into a language that is accessible to a group of non-expert decision-makers (e.g., the jury in a criminal trial, or a group of legislators). Yet one might worry that, far from solving the problem of accessibility, this only injects further uncertainty into the process, concerning what may have been inadvertently 'lost in translation' and what may have been deliberately left out - whether in the interest of simplicity or in order to advance a hidden agenda on the part of the putative expert. Goldman's fourth recommendation - that is, to be alert to, and look for, 'evidence of the experts' interests and biases vis-à-vis the question at issue' (Goldman 2001: 93) - certainly is an apt one in this context. At the same time, an inquiry into potential limitations of the scope, relevance and accuracy of the expert's claims, or indeed his expertise and track record, often is itself an integral part of public hearings and may even be undertaken by other experts who are at odds with the expert in question. From the perspective of the layperson, this opens up the possibility of arriving at an indirect assessment of the putative experts, by judging their argumentative performance relative to one another. If one speaker displays 'dialectical superiority' (Goldman 2001: 95) over the other, the lay hearer may take this as a prima facie indicator of his greater expertise.

For Goldman, dialectical superiority consists not merely in 'greater debating skill' - in the sense of a speaker's ability to get his target audience to adopt his views 
(as a defence lawyer addressing a criminal jury might) - but rather superiority in engaging the opposing party (in this case: the other expert) on their own terms. If, for example, $E_{1}$ manages to offer what appears to be a convincing rebuttal whenever $E_{2}$ makes a positive claim, whereas $E_{2}$ keeps changing the topic, rather than rebutting any of $E_{1}$ 's argument, the hearer $H$ may regard such dialectical superiority as a prima facie indicator of $E_{1}$ 's greater expertise. Note that, in order to make assessments of dialectical performance, it is not always necessary that $H$ be able to assess the content or validity of either $E_{1}$ 's or $E_{2}$ 's arguments. While $H$ may lack the expertise to assess the esoteric content of the discourse between the two experts, she may very well have sufficient background knowledge and observational skill to identify when an expert offers a genuine rebuttal and when he is evading the question or changing the topic. Whether a rebuttal is 'genuine' depends less on the truth value of the corresponding claim (which may be esoteric to the layperson) than on its relevance in the sense that, if true, the rebuttal would undermine the opponent's thesis. Judgments of credibility may thus be made on the basis of dialectical superiority: Observed instances of dialectical superiority are indirect evidence of the corresponding expert's superior level of expertise. ${ }^{3}$ Importantly, however, such an 'inference to the better expert', while not foolproof, may well be within the reach of a non-expert, since indicators of dialectical superiority can often be assessed, even in the absence of expert knowledge of the assessor.

It is worth noting that indirect assessments of expertise need not be restricted to the hearer's (passively) observing the relative performance of two experts; by engaging a putative expert directly, and requesting arguments from him to support his conclusions, a non-expert may elicit relevant evidence also in the 'layperson/1-expert case'. As Jean Goodwin puts it, 'the layperson may want to monitor the effort the expert is putting in, either by direct observation (where possible), or by asking the expert to recount the process by which he made his judgment' (Goodwin 2010: 139):

Note that in doing so, the layperson is not seeking to second-guess the expert's judgments or review the evidence for herself. Instead, the expert's conspicuous ability to recite in detail the grounds of his judgments can give the layperson some confidence that he took pains to have grounds at all. (ibid.)

The role of the layperson as a participant in a dialogue (and, by extension, in an argumentative practice), becomes even more prominent once we are dealing not with the question of which of two experts to believe, but with appeals to expert opinion that are made in the context of a dialogue between two epistemic equals. Walton argues - not implausibly, given our earlier characterisation of the appeal to expert opinion as a request of the speaker to be treated as a 'mere conduit' for a (cited) expert $E$ (see Section 4) - that one can bring to bear a number of general critical questions, analogues of which would also apply to the case of direct interaction with a

\footnotetext{
${ }^{3}$ On this point, see also (Scholz 2009: 199).
} 
putative expert. ${ }^{4}$ Each of these questions - e.g., the expertise question ('How credible is $E$ as an expert source?' or the trustworthiness question ('Is $E$ personally reliable as a source?') - is to be understood as comprising more specific sub-questions. (See Walton 1997.) Thus, the expertise question may be explored by inquiring into the cited expert's academic credentials, his professional accreditations, or - in the case of science - his track record of peer-reviewed publications. Likewise, trustworthiness may be evaluated by his track record as a truthful testifier or, where such information is unavailable, by asking the speaker for evidence of $E$ 's choice of methods and overall conscientiousness.

Eliciting information about the cited expert $E$, through a series of critical questions, and revisiting such information, if necessary, throughout the dialogue with the speaker, is of obvious importance in assessing appeals to expert opinion.

However, when we accept such an appeal, we do not rely on the epistemic authority of the putative expert alone - we also rely on the speaker's functioning as a successful conduit for the expert's opinions. While the latter does not require special expertise on the part of the speaker, it does, of course, require that he is both able and willing to adequately recount the expert's opinions in relevant ways. With respect to competence and sincerity, a speaker's appeal to expert opinion needs to be treated with the same caution as any testimonial report - perhaps with more, given that we know how easy it is for a layperson to misinterpret an expert's pronouncements and how tempting it might be for an interested party to misrepresent what an expert said, if it serves their cause. However, unlike in the 'null setting' of one-off testimony, where the testifier's sincerity and competence are largely inscrutable to the hearer, participation in a persuasion dialogue allows the hearer to engage his interlocutor over time. Continuous engagement and critical questioning may reveal inconsistencies in the speaker's defence of $E$ 's epistemic authority, or weaknesses in his understanding of $E$ 's pronouncements (or of their relevance to the argument in question).

In the remainder of this section, I wish to sketch a framework for how a respondent in a persuasion dialogue can attempt to keep track of the proponent's appeals to external epistemic authorities, and revisit his assessments in the light of new evidence - where, crucially, such evidence need not consist in new extrinsic information, but may consist in (or be inferred from) argumentative moves within the dialogue itself. What I wish to argue for is a variant of the 'scorekeeping' model of conversation, first proposed by David Lewis (1979) and later developed into a pragmatic theory of inferential-role semantics by Robert Brandom (1994). Conversational score-keeping, for Lewis, is a way of explaining the tacit presuppositions and standards of acceptability of various utterances, as well as the shifting (yet rule-governed) boundaries of acceptability across different contexts. Whereas for Lewis the elements constituting the conversational score 'are things such as sets of presupposed propositions and boundaries between permissible and

\footnotetext{
${ }^{4}$ For a detailed discussion of Walton's six main questions, see Wagemans (this issue).
} 
impermissible actions, ${ }^{5}$, for Brandom 'conversational score' is to be specified in terms of deontic statuses and attitudes. Simplifying somewhat, on Brandom's account, deontic statuses are either commitments or entitlements, the former acting as constraints, the latter licensing certain conversational or inferential moves. ${ }^{6}$ Participants in a discursive practice may then acknowledge (explicitly adopt), undertake (implicitly adopt), or attribute (take another party as acknowledging or undertaking) various commitments or entitlements. By 'keeping score' on themselves and their interlocutors over time, participants in a discursive practice can jointly come to recognise the context and force associated with, and speech acts involved in, various utterances. Thus, in the paradigmatic case of assertion, the speaker both (publicly) acknowledges a doxastic commitment and (implicitly) 'undertakes all the commitments and entitlements that follow from the one acknowledged' (Scharp 2005: 209). Furthermore, as Scharp puts its rather succinctly,

a successful assertion (i.e., one in which the asserter is entitled to the commitment acknowledged) entitles other members of the conversation to undertake the same commitment. Successful assertions present commitments for public consumption. (Scharp 2005: 209)

Keeping score might seem a laborious task - too arduous, perhaps, for it to be a psychologically plausible mechanism, and indeed it has been suggested that Brandom's account of conversational scorekeeping is best understood as a rational reconstruction of the complex strategies and behaviours displayed by real-life interlocutors.

Rather than defend conversational scorekeeping as the basis of a universal theory of meaning, however, I here wish to suggest that a conscious effort at keeping track of one's interlocutor's (acknowledged and undertaken) commitments and entitlements, is a commendable strategy in dealing with appeals to expert opinions. Irrespective of whether conversational scorekeeping generalises to all kinds of speech acts and conversational moves, it may have its most natural application in the context of appeals to an external epistemic authority. Testimony, in the language of commitments and entitlements, can be described as a way of making entitlements (to doxastic commitments, e.g. the belief that $p$ ) available to others. Thus, one interlocutor, $A$, 'might acknowledge $p$ because she has attributed the commitment associated with it and entitlement to that commitment to someone else, from whom she inherits it by testimony' (Scharp 2005: 210). If $A$ then represents herself to $B$ as communicating an expert opinion, $p$, it is up to $B$ to judge whether to regard $A$ as indeed entitled to $p$. On what basis can $B$ make such a determination? For one, $B$ can probe more deeply - using the set of critical questions identified by Walton - into $A$ 's

\footnotetext{
${ }^{5}$ This is Brandom's (accurate) summary of Lewis's approach; see (Brandom 1994: 182).

${ }^{6}$ Here I borrow from Scharp's (2005) summary of Brandom, which also lists helpful examples of deontic statuses; thus, '[d]oxastic commitments correspond to assertions and belief, inferential commitments correspond to reasons, and practical commitments correspond to action' (Scharp 2005: 207).
} 
commitment to the original source $E$ 's standing as an epistemic authority regarding $p$. But $B$ also has at his disposal $A$ 's track record of commitments and entitlements throughout the course of the conversational exchange, which allows $B$ to check whether $A$ 's appeal to expert opinion, on a given occasion, is consistent with her earlier pronouncements. Should a mismatch arise, it is $A$ 's responsibility to justify her position - as well as her reliance on an external authority - by giving further reasons. ${ }^{7}$

Appealing to expert opinion, much like assertion, thus has what Brandom calls a 'default and challenge' structure: While it is possible to 'inherit' entitlements to a commitment (in this case: to an expert's opinion), and while it is prima facie legitimate to deploy such opinions in subsequent discourse with others, such default entitlement can be challenged by an interlocutor. What underwrites the speaker's appeal to an expert opinion is the assumption that, in Brandom's words, 'the authority granted by an assertion include[s] a reassertion license - a license to do just what the asserter did' (Brandom 1994: 242). By the same token, it must be possible 'for the claims of one interlocutor to have the significance of challenges to the claims of another' (ibid.) - hence $A$ 's default entitlement to (and deployment of) an expert's opinion can always be challenged by $B$, either by $B$ 's making an incompatible assertion (and, in doing so, himself incurring a corresponding burden of proof) or by $B$ 's withholding attribution of entitlement (to the expert opinion) to $A$. The degree of an epistemic agent's propensity to mount such challenges may be seen as an important mark of his epistemic character. Thus, one might use this model to distinguish between credulous, cautious, and sceptical interlocutors: Whereas 'a credulous agent will grant entitlement to commitments by default', 'a cautious agent will grant entitlement to commitments if not already committed to an incompatible claim', and a sceptical agent 'will grant entitlement to a commitment only if it survives justified (entitled) challenges to entitlement' (Kibble 2004: 26). As Brandom himself notes with respect to the default-and-challenge model, ' $[\mathrm{t}]$ here is no reason in principle that conflicts of this sort need to be resolvable' (Brandom 1994: 193) - but as long as $A$ and $B$ engage in a shared practice of tracking and coordinating their differences in epistemic outlook, the mere lack of substantial agreement does not render such attempts at resolution futile.

\section{Conclusion: argumentation and the end of inquiry}

At the beginning of this paper, I spoke of the need for a rapprochement between social epistemology and argumentation theory. The discussion in the preceding sections, I hope, has made vivid both why this need has arisen and wherein such a rapprochement might consist. Contemporary social epistemology has tended to

\footnotetext{
${ }^{7}$ It is, of course, entirely possible that $B$ wrongly attributed certain commitments to $A$ earlier, but even then it should be possible for $A$ to contribute to the resolution of such misunderstandings, for example by clarifying her position.
} 
oscillate between, on the one hand, a largely individualistic approach, which attempts to subsume all forms of reliance on the epistemic authority of others under the rubric of 'testimony' (thus allowing for the reframing of questions concerning the social dimension of inquiry in terms of the individual hearer's justification of his or her testimonial beliefs), and, on the other hand, wholesale scepticism about the individual's role in controlling her epistemic situation. ${ }^{8}$ Yet a moment's reflection shows that the truth about our epistemic predicament must lie somewhere in between these two extremes. How else would it be possible to explain the overall success of our various testimony-dependent collective projects, such as science, history, or education, which each of us is indebted to for much of our knowledge? ${ }^{9}$

Argumentation theory provides us with the formal tools for the analysis of persuasive dialogues and texts, in specific circumstances, including in the case of appeals to expert opinion. Yet, as Goodwin rightly points out, there remains 'a gap between the very general puzzle presented by expert opinion and the very specific methods developed to deal with it' (Goodwin 2010: 136). If one regards the latter as the domain of argumentation theory and the former as the way in which the problem of expertise has traditionally been discussed in social epistemology, then a rapprochement between the two holds the promise of providing the very 'theory of the middle range' which Goodwin identifies as a desideratum.

Several starting points for such a rapprochement were discussed in this paper. In particular, Goldman's list of five types of evidence a recipient of expert testimony might bring to bear on her assessment of what she has been told (see Section 2) coheres well with the critical questions identified by Walton (see Section 4) in his discussion of how to respond to appeals to expert opinion. Similarly, the language of deontic commitments and entitlements lends itself to an analysis of argumentative scenarios, especially in the case of persuasion dialogue - where 'persuasion' here refers not to the psychological phenomenon of actual belief change, but to 'a kind of commitment-based rational persuasion within the framework of a dialogue and the moves made therein' (Walton 2008: 176). Conversational scorekeeping - irrespective of whether or not it can serve as a viable basis for a universal theory of meaning suggests itself as an evidential 'backtracking' strategy, allowing an interlocutor to revisit her earlier assessments by treating her conversational partner's argumentative moves as themselves indirect evidence of his reliability. Importantly, as noted at the end of the previous section, conversational scorekeeping - even in the face of substantial disagreement - must take place against the backdrop of a shared practice

\footnotetext{
${ }^{8}$ Recall Hardwig's contention that, if I do not have access to both, a putative expert's reasons and a justification of why these are good reason, then 'I am in no position to determine whether the person really is an expert' (Hardwig 1985: 340).

${ }^{9}$ For an argument that the success of our testimony-based collective projects can abductively sustain a stance of default acceptance of testimony, to be counterbalanced by specific instances of rejection 'whenever the best explanation of the circumstances of its production (including the fact that it has been produced) casts doubt on the reliability of what we are told', see (Gelfert 2010: 395).
} 
of recognising, tracking, and coordinating differences in epistemic outlook. Without such agreement, no participant could expect his or her arguments to have any probative force for their opponent, let alone induce a state of rational persuasion in the latter. At the same time, this observation provides a hint as to when an appeal to authority is legitimate and when it constitutes a fallacy: For an appeal to expert opinion to be legitimate (though, of course, not necessarily successful), it must be possible, at least in principle, for the hearer to challenge it - not indiscriminately, but in a way that allows the hearer first to ascertain whether he and the speaker are indeed engaged in the same activity (e.g., rational discussion rather than mere assertion of brute power) and, second, to probe the epistemic authority of the cited source. By contrast, the most common type of the fallacy of authority is the case where, as Walton puts it, 'an appeal to expertise (cognitive authority) is confused with an appeal to institutional authority, particularly where the institutional authority is portrayed as having a finality or absolute authority that admits of no critical questions' (Walton 1997: 252).

I wish to conclude by relating the question of expertise, including appeals to expert opinion, back to that core question of epistemology: 'What is knowledge?' In recent years, a strand of epistemology has gained currency that attempts to answer this question not by engaging in conceptual analysis (e.g., 'knowledge is a species of justified true belief'), but by inquiring into the function of the concept. One suggestion has been that attributions of knowledge function as an 'inquiry-stopper' (Kappel 2010: 74). The basic idea is that the concept of knowledge has arisen from a conceptual need - one that is plausibly experienced by any population of epistemically interdependent beings - for 'tagging' instances where inquiry has, for all intents and purposes, been taken far enough. The concept of knowledge may then be thought of as a solution to the epistemic coordination problem of indicating collective agreement on when inquiry has reached closure. ${ }^{10}$ Is it perhaps possible to think of the notion of expertise along similar lines? If a proponent of a thesis appeals to expert opinion in the course of trying to rationally persuade a respondent, the dual goal of such dialogue is both to get the respondent to make the transition from lack of commitment to rational acceptance of the proponent's thesis and to make further inquiry unnecessary - at least for the time being. Likewise, within the parameters of a shared practice of rational discourse (and given the 'default and challenge' structure outlined in the previous section), failure of a respondent to offer further challenges to a proponent's appeal to expert opinion - provided the appeal has been properly advertised as such, and has been acknowledged by the respondent - may well be legitimately construed as tacit agreement that inquiry concerning the point in question has, at least for now, been taken far enough. This is not to downplay the importance of being vigilant against the conflation of epistemic authority with social power - lest dialogue and inquiry be terminated prematurely, and for the wrong reasons.

\footnotetext{
${ }^{10}$ For a broader, multicausal analysis of the concept of knowledge as an adaptive response to a combination of selective pressures and conceptual needs, see (Gelfert 2011).
} 


\section{Acknowledgments}

I am grateful to Boaz Miller and the participants of the March 2011 workshop 'Epistemic Practices: Knowing through Testimony', held at the Institute for Advanced Studies in the Humanities, University of Edinburgh, for valuable comments on an earlier draft of this paper.

\section{References}

Adler, Jonathan. 2010. Epistemological problems of testimony. In Edward N. Zalta, The Stanford Encyclopedia of Philosophy (Winter 2010 Edition), http://plato.stanford.edu/archives/win2010/entries/testimony-episprob/. Accessed 20 February 2011.

Brandom, Robert B. 1994. Making It Explicit: Reasoning, Representing, and Discursive Commitment. Cambridge (Mass.): Harvard University Press.

Coady, C.A.J. 1992. Testimony: A Philosophical Study. Oxford: Oxford University Press.

Gelfert, Axel. 2010. Reconsidering the role of inference to the best explanation in the epistemology of testimony. Studies in History and Philosophy of Science 41: 386-396.

Gelfert, Axel. 2011. Steps to an ecology of knowledge: continuity and change in the genealogy of knowledge. Episteme: A Journal of Social Epistemology 8: 6782 .

Goldberg, Sanford. 2010. Relying on Others: An Essay in Epistemology. Oxford: Oxford University Press.

Goldman, Alvin. 1999. Knowledge in a Social World. Oxford: Oxford University Press.

Goldman, Alvin. 2001. Experts: which ones should you trust? Philosophy and Phenomenological Research 63: 85-110.

Goodwin, Jean. 2010. Trust in experts as a principal-agent problem. In Dialectics, Dialogue, and Argumentation, ed. Chris Reed and Christopher W. Tindale, 133-143. London: College Publications.

Hardwig, John. 1985. Epistemic dependence. The Journal of Philosophy 82: 335-349.

Hardwig, John. 1991. The role of trust in knowledge. The Journal of Philosophy 88: 693-708.

Hume, David. 1748. An Enquiry Concerning Human Understanding. Ed. by Tom L. Beauchamp, 2000. Oxford: Oxford University Press. 
Kappel, Klemens. 2010. On saying that someone knows: themes from Craig. In Social Epistemology, ed. Adrian Haddock, Alan Millar, and Duncan Pritchard, 69-88. Oxford: Oxford University Press.

Kauffeld, Fred J., and John E. Fields. 2003. The presumption of veracity in testimony and gossip. Proceedings of the 2003 OSSA Conference. Windsor: University of Windsor. http://web2.uwindsor.ca/faculty/arts/philosophy/ILat25/. Accessed 20 February 2011.

Kibble, Rodger. 2004. Elements of a social semantics for argumentative dialogue. In Working Notes of the 4th Workshop on Computational Models of Natural Argument (CMNA 2004), ed. Floriana Grasso, Chris Reed, and Giuseppe Carenini, 25-28. Valencia: Universidad Politecnica.

Kitcher, Philip. 1994. Contrasting conceptions of social epistemology. In Socializing Epistemology: The Social Dimensions of Knowledge, ed. Frederick F. Schmitt, 111-134. London: Rowman and Littlefield.

Kusch, Martin. 2002. Knowledge by Agreement: The Programme of Communitarian Epistemology. Oxford: Oxford University Press.

Lewis, David. 1979. Scorekeeping in a language game. Journal of Philosophical Logic 8: 339-359.

Matheson, David. 2005. Conflicting experts and dialectical performance: adjudication heuristics for the layperson. Argumentation 19: 145-158.

Olmos, Paula. 2008. Situated practices of testimony: a rhetorical approach. Theoria 61: 57-68.

Scharp, Kevin A. 2005. Scorekeeping in a defective language game. Pragmatics \& Cognition 13: 203-226.

Scholz, Oliver R. 2009. Experts: what they are and how we recognize them - a discussion of Alvin Goldman's views. Grazer Philosophische Studien 79: 187-205.

Strevens, Michael. 2010. In Oxford Studies in Epistemology Vol. 3, ed. Tamar Szabó Gendler and John Hawthorne, 294-330. Oxford: Oxford University Press.

Wagemans, Jean. 2011. The critical assessment of the argument from expert opinion. Argumentation (forthcoming).

Walton, Douglas. 1997. Appeal to Expert Opinion: Arguments from Authority. University Park: Pennsylvania State University Press.

Walton, Douglas. 2008. Witness Testimony Evidence: Argumentation, Artificial Intelligence, and Law. Cambridge: Cambridge University Press.

Williams, Bernard. 2002. Truth and Truthfulness: An Essay in Genealogy. Princeton: Princeton University Press. 